\title{
Reducing failures rate within the project documentation using Building Information Modelling, especially Level of Development
}

\author{
Kristýna Prušková1 ${ }^{*}$ \\ ${ }^{1}$ Faculty of Civil Engineering, Czech Technical University, 16629, Prague, Czech Republic
}

\begin{abstract}
Paper's focus is on differences between traditional modelling in 2D software and modelling within the BIM technology. Research uncovers failures connected to the traditional way of designing and construction of project documentation. There are revealed and shown mismatches within the project documentation. Solution within the Building information modelling Technology is outlined. As a reference, there is used experience with design of specific building in both ways of construction of project documentation: in the way of traditional modelling and in the way when using BIM technology, especially using Level of Development. Output of this paper is pointing to benefits of using advanced technology in building design, thus Building Information Modelling, especially Level of Development, which leads to reducing failures rate within the project documentation.
\end{abstract}

\section{Introduction}

At current times, there are several ways of project documentation's construction used. It is a mixture of traditional ways and modern technologies. We can find architects who still design with a pen and a paper and, on the opposite site, architects using the most advanced technologies for design.

\subsection{Different approaches to project documentation's construction}

The aim of this paper is to reveal the research of differences between using traditional way of building design in 2D software (or simply drawings) and using an advanced technology called BIM - Building Information Modelling from the building designer's perspective and consequences connected to using these different technologies. As a reference for the comparison of these two different approaches to the construction of project documentation is used experience from construction of project documentation of specific building.

\footnotetext{
* Corresponding author: pruskova@mail.vstecb.cz
} 


\subsection{Processes needed within the construction of project documentation}

In the traditional way, there are drawings in 2D. Every drawing should correspond to other, for example, elements shown in the floor plan must be also shown and exactly shown in the same place in other drawings as section plan, etc. This develops high demands on the designer's imagination and precision of his work. This way of modelling building design, unfortunately, gives a space for the human failures that can be revealed in other phases of building life cycle.

The other part of the building design is a coordination of processes that must be done between the participants of special parts of documentation. Because of project documentation is usually constructed by more participants, it is necessary to provide effective communication between them. These participants are entering the design process in different phases of project documentation's development and with different request for information (RFI). Every participant who enters to the design process makes changes in the design according to his profession. At first, there is an architect, who gives the main idea of a building design. Then there is a building designer who is usually responsible for the whole project documentation and who provides all the coordinating communication and information transfer necessary for the good comprehension and conjunction of all the professional parts of documentations. The responsible building designer needs to develop a plan for his coordinating activities. The main part of these activities is project work division between other participants and determining their accountabilities.

\subsection{Project documentation required legislation in Czech Republic}

Project documentation of building contains a lot of information about the design of building or a construction in a widely way. There are generally several participants, who contribute to design of the building. Each participant has responsibility for different part of this design and for his part of project documentation's construction. Current Czech Republic's Legislation demands the project documentation in the form of file with paper documents. The file must be in prescribed structure. There are no demands for the digital form of documentation within the legislation. The structure divides documentation to many parts. These parts are usually elaborated by different project participants according to their specialization and professional orientation. The documentation parts need to correspond to each other. That's why there is huge time-consuming and demanding thinking process, which must coordinate all the participants.

During the design process, there are a lot of phases, when each participant do the proposal, then the assessment of the proposal and all proposed data are analysed. When the proposal's analysis is sufficient to all aspects of the design project, after that the participant is able to finish his work. But when there are conditions, not satisfying project design, it's necessary to do the changes in order to satisfy all conditions. These project changes should be announced to all other participants. Participants have to accept these changes and there is a probability that several changes would be unacceptable for some participants and that's the reason for other changes. This process seems to be very complicated.

\subsection{Traditional way of building design - modelling in 2D software}

Using 2D software means construction of drawings by the lines and texts. Construction of documentation using traditional technology demands great coordination between participants and each participant is highly loaded by the processes connected with the design.

The main problem in a traditional way of modelling in coordination of all participants' work is in data sharing. In current times, there are project participants with different 
knowledge and experience and there are a lot of software possibilities. That's why there is used lot of different platforms and data formats used within a single project. Every participant works with different software, which is the most suitable for their own knowledge and experience and for their profession. It means that every participant has different approach to create a documentation, which makes him feel comfortable to use for his part of work. Shared data are transformed into different software and with different information contained. That means that every participant works on his own data model. Consequences are different request for information (RFI), because every participant uses different information relevant for their part of the work on a project design. Next to these requests for information there is a high probability in disinformation are misunderstandings, which may cause the undesirable changes in the project. These aspects are the main causes of failures within the project documentation. Because every single change needs to be inscribed into each data model used with all participants in order to create a collection of suitable documentation parts, which correspond to each other.

\section{Using BIM Technology}

A simple misunderstanding or disinformation in the project documentation may cause the huge and especially expensive reparation in the following phases in building life cycle. Using BIM Technology not only in building design leads to reduction of failures within the project documentation. According to the Podmanický and Nývlt (2015), the BIM technology is becoming a useful tool not only for its attractive visualization and presentation outcomes [1].

\subsection{Comparison of effort and effect according to the Graphic Curve by Patrick MacLeamy from HOK}

The Patrick MacLeamy's graphic curve on the Effort (and Effect) expended on the phases of building life cycle says two important things:

- 1) The better is project developed, the less costs are invested into design changes.

That means that well-prepared pre-design, when the ability to influence the costs and performance is on the highest level, decrease the possibility of needed costly design changes in the following life cycle phases. On the opposite site, pre-design that has to be developed with changes or modification in further life cycle phases is more demanding for efforts and, of course, cost.

- 2) The efforts made on the project documentation created by using traditional technology and by using BIM technology are approximately the same (according to the area under the Mac Leamy's curve. But it differs in the amount of efforts made in different phases of building lifecycle.

Traditional technology demands the most efforts in the phase of construction project documentation. The BIM technology, compared to that, demands the more efforts earlier in the building life cycle. It's in the phases of schematic design and mainly in the phase of design development, when the ability of influence costs and performance of the building is on a higher level than in the phase of construction project documentation. 


\section{Shifting the Curve to the Left}

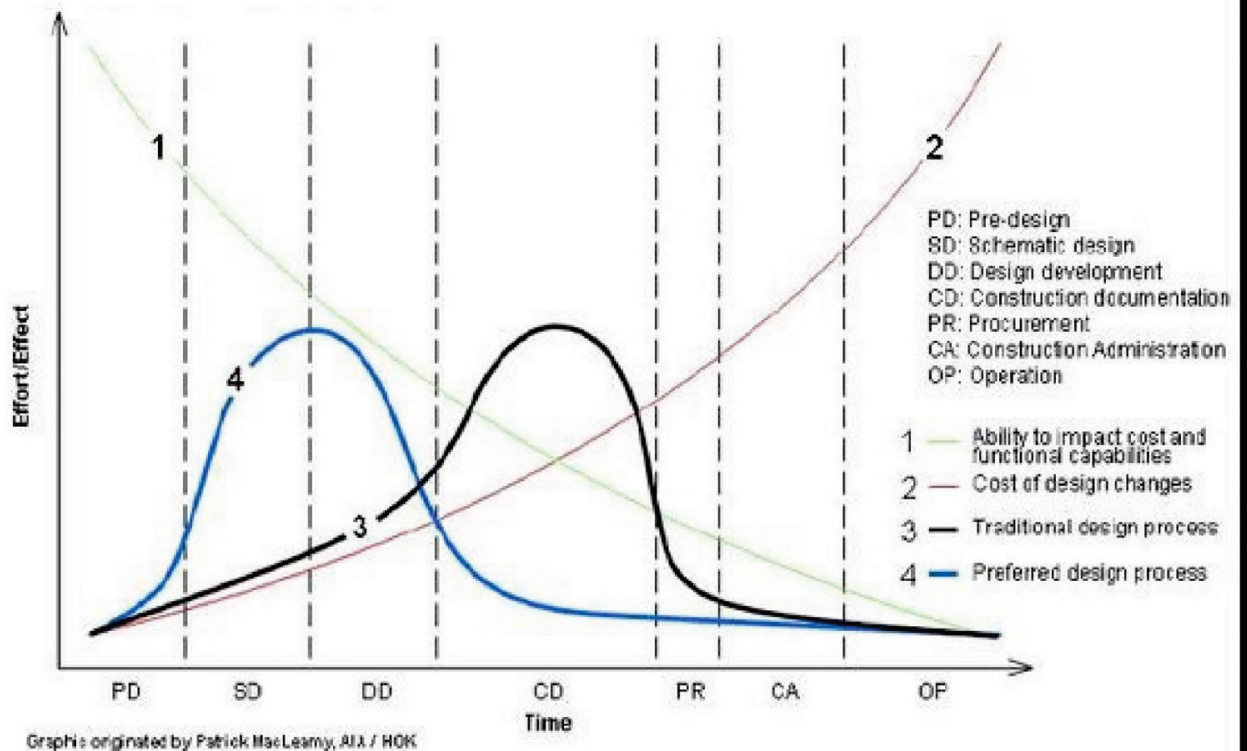

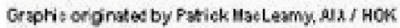

Fig. 1. Graphic originated by Patrick MacLeamy, AIA / HOK [2].

That's why the BIM technology is considered to be a better way for building design in many aspects. It's reflected in decreasing rate of failures that revealed during the building life cycle thus also in cost of project modifications and, of course, in time that is necessary to provide demanded changes or modifications of the project. The knowledge management is the integral part of the processes needed to perform using BIM Technology. "The need of knowledge management primarily comes from BIM's lack of tolerance to erroneous or missing information" [3].

\section{Using of Level of Development as a tool for definition}

There are many terms used in connection to the levels and project phases. We can talk about Level of Detail, which informs how much detailed information is included in the element model, or about the Level of Information. The Level of Development (LOD) helps to define the amount of information given to element or group of elements in different part of the building life cycle [4].

Every model contains a lot of elements in different phases of progress within the building life cycle. LOD is a tool, which helps determine these phases a thus the reliability of information contained about the element [5]. The preciousness of elements' definition in the LOD language is secured by the Level of Development Specification, which is at least annually actualized according to the new experiences with this technology and the progress of using this technology. The LOD is divided into levels LOD100, LOD200, LOD300, LOD350, LOD400 and even LOD500 according to the project's progress and the amount of information requested in the different phases [6]. LOD contributes to better orientation and visualization of information contained in project model. 


\section{Management with using BIM Technology}

BIM Technology itself doesn't contain the management of knowledge, but it can be a very useful tool in a connection of well-prepared plan of processing of knowledge. Extracted knowledge from building information model can be useful not only for design and build processes but also for all other processes that may use information about building [7]. The management of processes within the using BIM Technology can be ensured by BIM Project Execution Plan. Definition of BIM project scope can be done using definition of priority of requirements [8]. "Principles of creation of BIM Project Execution Plan is based on definition of BIM Goals that are achieved through the application of BIM Uses" [9]. This plan of processes ensured the most suitable plan for using BIM Technology that finally helps to all participants within the design process to be well oriented in the model and its project phases and to be able to carry out the most efficient work done. Such process models are usually based on Business Process Model and Notation standard or its adaptations [10] and offers mainly behavioural view of the process. This view can be extended by adding more information about structure of participants [11] and states of process that allows better process effectivity measurement $[12,13]$.

\section{Conclusion}

From the building designer's perspective, BIM Technology is a very useful tool for better coordinated work of participants within the whole building life cycle. BIM model itself has high-level demands on information. It ensures the higher quality of not even the project documentation, but of the project design itself. Using this technology lighten the difficulty of processes that has to be carried out by people's thought in a traditional way of modelling. Thu human factor in traditional way of modelling my cause many failures of different scale due to the high demands on human's imagination and experiences. The BIM Technology doesn't allow most of these failures, because it can ensure the precious sharing a developing of information used within the whole project life cycle. Widely using of enhanced BIM technology will leads to the higher quality of project design and, without dispute, to the sustainable development of buildings and structures.

This work was supported by the Grant Agency of the Czech Technical University in Prague, grant No. SGS16/200/OHK1/3T/11

\section{References}

1. P. Podmanický, V. Nývlt, International Multidisciplinary Scientific GeoConference Surveying Geology and Mining Ecology Management, SGEM 2015 2(6), 377-384, (2015)

2. AIA. Available on https://www.aia.org

3. V. Nývlt, K. Prušková, IOP Conf. Ser.: Mater. Sci. Eng. 245, 042070 (2017)

4. K. Prušková, International Multidisciplinary Scientific GeoConference Surveying Geology and Mining Ecology Management, SGEM 2017 17(62), 821-826, (2017)

5. C. Eastman, BIM Handbook. (2011)

6. Level of Development Specification. Available on http://www.bimforum.org/lod

7. R. Pinka, J. Kaiser, International Business Information Management Association (IBIMA), 2602-2616 (2017)

8. J. Myslín, J. Kaiser, International Business Information Management Association (IBIMA), 4002-4013 (2017) 
9. Building Information Modeling Project Execution Planning Guide and Templates: Version 2.0. Available on http://bim.psu.edu/

10. J. Kaiser, CESB 2016 - Central Europe Towards Sustainable Building 2016: Innovations for Sustainable Future, 781-788 (2016)

11. J. Myslín, J. Kaiser, J, Multi-role Activities in BIM Execution Plan, Advanced Science Letters (will be published)

12. J. Myslín, J. Kaiser, International Business Information Management Association (IBIMA), 3598-3606 (2017)

13. J. Kaiser, J. Myslín, J. Rádl, Process Management in Building Industry(ČVUT, Praha, 2016) 